\title{
Belgian flood risk governance: explaining the dynamics within a fragmented governance arrangement
}

\author{
H. Mees ${ }^{1}$ (D) A. Crabbé ${ }^{1}$ and C. Suykens ${ }^{2}$ (D) \\ 1 Faculty of Political and Social Sciences, Society and Environment, Antwerp University, Antwerpen, Belgium \\ 2 Utrecht Centre for Water, Oceans and Sustainability Law, Utrecht, Utrecht University, Netherlands
}

\section{Correspondence \\ Hannelore Mees, Faculty of Political and Social Sciences, Society and Environment, Antwerp University, Sint-Jacobsstraat 2, Antwerpen 2000, Belgium. \\ Email: hannelore.mees@uantwerpen.be}

DOI: $10.1111 / \mathrm{jfr} 3.12330$

Key words

Belgium; flood risk governance; fragmentation; gradual transformation; path dependency; policy arrangement approach; stability and change.

\begin{abstract}
Despite some inertia, flood risk governance in Belgium has been fairly dynamic between 1995 and 2015. In this paper, change and stability during this period are described and explained in the four dimensions of the Policy Arrangement Approach: actors, discourses, rules, and resources. The analysis is based on 72 semi-structured stakeholder interviews and legal document analysis.

Belgian flood risk governance is characterised by a high level of fragmentation. Our analysis found that this can form a barrier to change, but at the same time it creates multiple entry points for policy innovation and thereby increases the dynamics within the governance arrangement.
\end{abstract}

\section{Introduction}

When investigating stability and change in flood risk governance (FRG), Belgium is an interesting case because of its specific governmental characteristics. In the federal state of Belgium, the three regions (Flanders, Wallonia and Brussels-Capital Region) are fully competent for water management and spatial planning, whereas emergency planning and insurance policy are governed at federal level. This institutional reality has resulted in fragmented FRG, with a large number of actors and legal frameworks on four governmental levels (municipal, provincial, regional, and federal).

Our starting hypothesis is that this complex multi-level governance (MLG) setting can have a double impact on the dynamics of FRG. On the one hand, fragmentation could be expected to hamper the diffusion of innovation within FRG because change in one organisation is not automatically adopted by others. On the other, it can create multiple entry points for new ideas. Once an innovation develops in one of the organisations involved, policy entrepreneurs and advocacy coalitions can emerge to spread ideas to other stakeholders (Hajer, 1995). The fragmentation degree thus gives the governance arrangement a more open character, which can make it more dynamic (Termeer et al., 2011; Kaufmann et al., 2016).
The central research question in this paper is: 'To what extent has flood risk governance in Belgium undergone change in the period 1995-2015 and how can this be explained?' The research conducted to answer this question was carried out in the framework of STAR-FLOOD, an EUfunded FP7 project, which investigated FRG in six Member States. The evaluation uses qualitative research methods (Section Methods) and focuses on the governance of fluvial flooding in the two largest regions of Belgium: Flanders and Wallonia (Section Overview of Belgian FRG). The paper describes the shifts that have taken place (Section Dynamics in Belgian FRG), through which kind of transformation processes they have developed and how these changes (or their absence) can be explained (Section Explaining Governance Dynamics). Particular attention is paid to the impact of the country's fragmented MLG structure on stability and change. The paper uses the Policy Arrangement Approach (PAA), introduced in the section below, to analyse and explain factors of stability and change in the governance arrangement (Section Conceptual Framework).

\section{Conceptual framework}

In the introductory article of this special issue, Wiering et al. (2018) offer theoretical backgrounds and working 
hypotheses for the empirical study of stability and change in FRG. On the one hand, they elaborate theories of path dependency and institutional stability; on the other, they focus on the role of policy entrepreneurs and actorcoalitions bringing new ideas on how policies should be organised. Furthermore, they consider the role of trends and shock events.

Based on their literature review, Wiering et al. (2018) composed a table containing 'forces of stability' as well as 'forces of change' (see Table 1). They relate these forces to four dimensions discerned in the PAA: actors and coalitions, rules, resources, and discourses. Within this approach, policy arrangements have been defined as ' $a$ temporary stabilisation of the content and organization of a policy domain' (Van Tatenhove et al., 2000). The PAA links up all relevant dimensions of a policy domain (actors, discourses, rules, and resources) and hence enables a study of the policy arrangement as a whole. By studying the development within these dimensions over time, the degree of stability or change in the arrangement can be analysed.

The forces of stability and change mentioned in Table 1 are used hereafter as guiding 'hypotheses' for explaining stability and change in Belgian FRG.

Our conceptual framework is further strengthened by the insights of Streeck and Thelen (2005). On the one hand, their model of gradual transformation retains close connections to path dependency literature. On the other, most of the processes of gradual transformation described by Streeck and Thelen are in fact induced by specific change agents - policymakers, implementers, social groups - who perceive the current institutional arrangements as suboptimal, due for instance to newly emerging actors, a shifting balance of power or new scientific insights.
Streeck and Thelen discern five modes of gradual transformation. In the cases of displacement and layering, existing institutions basically remain in place but are gradually dominated by new ones (displacement), or existing and new institutions accumulate (layering). Also in the case of drift, existing institutions may formally remain in place (Streeck and Thelen, 2005, p. 29), but they are hollowed out 'from below' because actors on the ground start to develop alternative ways of dealing with the issues at stake. In the two remaining modes, existing institutions are themselves affected and transformed. Under conversion, they adapt to new goals or interests. Exhaustion, finally, denotes a process by which an institution begins to yield declining rather than increasing returns (Streeck and Thelen, 2005, p. 30), leading to a process of institutional selfundermining.

\section{Methods}

The research for this article was carried out in the framework of the EU-funded FP7 STAR-FLOOD project (www. starflood.eu), which compares FRG in six EU Member States. The article is based on the content of the project's deliverable report on Belgium, which describes and evaluates the evolution of FRG in the country between 1995 and 2015 (Mees et al., 2016). This period was chosen for analysis because a number of significant flood events took place and important legislative and policy-related initiatives were launched, both at EU and national level. Due to the unique situation in the Brussels Capital Region, we focused on the Flemish and Walloon regions. The research was conducted via document analysis and semi-structured interviews, both at national/regional level and in three local case studies,

Table 1 Forces of stability and change according to the PAA dimensions (source: Wiering et al., 2018)

\begin{tabular}{|c|c|c|}
\hline Forces of stability & Dimensions of arrangements & Forces of change \\
\hline $\begin{array}{l}\text { - Coordination effects: Governance is sedimented in } \\
\text { specific divisions of accepted responsibilities }\end{array}$ & Policy actors and coalitions & $\begin{array}{l}\text { - Policy entrepreneurs: Highlighting perception } \\
\text { of sub-optimality of governance and } \\
\text { approach } \\
\text { - Advocacy coalitions: Strong pressure by specific } \\
\text { interests }\end{array}$ \\
\hline $\begin{array}{l}\text { - Fixed costs and increasing returns through large } \\
\text { investments in flood infrastructure (sunk costs) } \\
\text { - Learning effects: Evolution of strong expert body } \\
\text { of knowledge and strong epistemic community }\end{array}$ & Power and resources & $\begin{array}{l}\text { - Economic developments: Increasing costs of } \\
\text { flood infrastructure/maintenance or sudden } \\
\text { financial cutbacks, opening alternative } \\
\text { options } \\
\text { - New expertise (learning) }\end{array}$ \\
\hline $\begin{array}{l}\text { - Law has an important stabilising effect on the } \\
\text { formalisation of rules and procedures }\end{array}$ & Rules of the game & $\begin{array}{l}\text { - Decreasing legitimacy of rules } \\
\text { - New rules (e.g. EU Floods Directive) }\end{array}$ \\
\hline $\begin{array}{l}\text { - Strong historical narratives } \\
\text { - Adaptive expectations: Public trust in existing } \\
\text { institutions and their efficiency }\end{array}$ & Policy discourses & $\begin{array}{l}\text { - Diminishing trust in existing institutions and } \\
\text { their efficiency } \\
\text { - New ideas, new problem definitions and policy } \\
\text { concepts leading to counter-narratives }\end{array}$ \\
\hline
\end{tabular}


Table 2 Number of interviews per stakeholder type

\begin{tabular}{|c|c|c|}
\hline & Flanders & Wallonia \\
\hline Federal public administration & & \\
\hline Regional public administration & 12 & 10 \\
\hline Provincial public administrations & 5 & 6 \\
\hline Local public administrations & 12 & 4 \\
\hline Flemish sub-basin boards & 5 & \\
\hline Walloon river contracts & & 5 \\
\hline Political representatives & 2 & \\
\hline Nongovernmental organisations & 7 & 2 \\
\hline Knowledge institutes & 1 & \\
\hline
\end{tabular}

i.e. in Antwerp, Geraardsbergen, and Lessines (Appendix S1, Supporting Information). In total, 72 governmental and nongovernmental stakeholders were interviewed in both Flanders and Wallonia. An overview of the number of interviews per stakeholder type is shown in the Table 2.

The results of the research were discussed with 72 governmental and nongovernmental stakeholders during a workshop on 25 March 2015, after which they were further refined. More detailed information on the methods used in our research can be found in Mees et al. (2016).

\section{Overview of Belgian FRG}

Belgium has undergone a series of substantial institutional reforms affecting the governance of fluvial flood risks over several years:

1. With the institutional reforms in 1980 and 1988, competences with regard to spatial planning, water management, and various other topics relevant to FRG were transferred to the regions ${ }^{1}$, whereas policymaking competences with regard to emergency planning and insurance schemes remained at the federal level.

2. The 2014 Sixth State Reform further transferred important competences to the three regions, e.g. with respect to ex post compensation following natural disaster events.

3. Within the regions, so-called internal state reforms took place, which further shuffled competences for FRG. These will be discussed in the sections below.

These reforms have resulted in a permanent state of change in the country.

In this section, we focus on two relationships of key importance in Belgian FRG, namely the relationship between water management and spatial planning (Section Water Management and Spatial Planning) and between emergency planning and insurance policy (Section Emergency Planning and Insurance Policy).

\footnotetext{
${ }^{1}$ Article 6, Section 1 of the Special Act on Institutional Reform of 8 August 1980
}

\section{Water management and spatial planning}

Regional competences for water management are highly fragmented in terms of actors. Both in Flanders and Wallonia, the management of watercourses is split into four categories, each with a different set of water managers. These actors are divided over three governmental levels, namely regional, provincial, and municipal. At sub-local level, some watercourses are in the hands of a polder or wateringue composed of riparian landowners. Spatial planning is also addressed at regional, provincial, and municipal level.

The principal legislative act on FRG in Flanders is the 2003 Decree on Integrated Water Policy (DIWP), which was substantially reformed in 2013. The main instrument for flood risk prevention included in this decree is the water assessment, which obliges authorities to request advice from the relevant water manager on the impact of a permit, plan or programme on the water system (article 8 DIWP). In Wallonia, FRG is mainly steered by the Plan PLUIES (2003) and the Water Code (2004). The Plan PLUIES is a strategic document whose main innovation is the introduction of flood cartography. Similar to the water assessment in Flanders, article 136 of the CWATUP ${ }^{2}$ enables Walloon authorities to request the advice of water managers on spatial planning. However, in contrast to the Flemish Region, this request is not compulsory and the legal framework is less prescriptive on the thresholds for advice, the scope of the instrument and the criteria applied.

Besides spatial planning tools, the DIWP and Plan PLUIES have created specific bodies to better coordinate water management and spatial planning. In Flanders, this coordination is undertaken by the Coordination Commission on Integrated Water Policy (CIW), and in Wallonia by the Interdepartmental Flood Group (GTI).

\section{Emergency planning and insurance policy}

In contrast to water management and spatial planning, policymaking in emergency planning and insurance policy is primarily situated at federal level although some emergency planning activities are also developed at provincial and municipal level.

The main legislative act in terms of emergency planning is the Royal Decree of 16 February 2006, which harmonised emergency plans at different policy levels.

In order to strengthen flood recovery, flood damage was added to the general fire insurance policy through the Act of 17 September 2005 on the Insurance of Natural Disasters. Flood damage not covered by insurance can in certain

\footnotetext{
${ }^{2}$ The Code wallon de l'aménagement du territoire, de l'urbanisme et $d u$ patrimoine (CWATUP) comprises the main legislative framework for spatial planning in the Walloon Region.
} 
cases be compensated through the public disaster fund. This fund was transferred to the regional governments by the 2014 Sixth State Reform (see Mees et al., 2016).

\section{Dynamics in Belgian FRG}

Between 1995 and 2015, Belgian FRG altered significantly. Change occurred incrementally but its impact has been considerable. The main shifts observed are the rise of nature-based water management, an enhanced coordination between governmental actors and shifting flood risk responsibilities.

\section{Towards creating space for water}

Belgian FRG is deeply rooted in flood defence. Over the centuries, a strong infrastructural network of levees, weirs, pumps, etc. has been created to reduce the probability of flooding. Within the period investigated, however, the approach has shifted from protecting the land as a whole to distinguishing between the protection of vulnerable and less vulnerable areas. Both in Flanders and Wallonia, there has been a shift from a flood policy based on rapid water drainage to creating space for water. This new approach became particularly apparent around the turn of the century following flood events in 1998 and 2002-2003 (Mees et al., 2016). Since then, the Flemish and Walloon governments have established programmes for the installation of flood retention zones, depolderisation and river restoration. The restoration of rivers and floodplains not only aims to enhance flood safety, but often also has a dual function of ensuring water quality and meeting biodiversity objectives. This is for example prominent in the tidal Scheldt basin, where a cooperation between knowledge institutes, water, and nature managers has led to a new type of flood control areas (i.e. FCAs with reduced tide).

Hence, the shift towards creating space for water generates entry points for integrating water quality and quantity management. This integration can also be observed in legislation. Both the Flemish and Walloon Regions have integrated the implementation of the EU Water Framework Directive (WFD) (2000/60/EC) and Floods Directive (FD) (2007/60/EC) in a single legislative document, namely the DIWP in Flanders and the Water Code in Wallonia. In the Flemish Region, integration has extended to the implementation phase; the first cycle of Flood Risk Management Plans, pursuant to the FD, has been integrated in the second cycle of River Basin Management Plans demanded by the WFD.

The shift towards creating space for water in both regions has been accompanied by the introduction of new spatial planning instruments. These instruments bridge water management with spatial planning and thus mitigate to some extent the organisational fragmentation. In Flanders, the 2003 DIWP introduced the water assessment. Moreover, the Flemish government is experimenting with other innovative spatial planning instruments (e.g., signal areas $^{3}$, land consolidation, etc.) to reduce the impact of urbanisation on the water quantity system. The duty-toinform raises citizens' awareness, with all real estate publicity being obliged to disclose the flood-prone character of a location. In Wallonia, steps are also being taken to integrate spatial planning in water policy although in a legally less stringent manner.

The increased attention to nature-based flood protection and spatial planning measures forms an addition to rather than a replacement of the existing flood defence infrastructure. In the field, the more classical flood defence measures remain an important pillar of FRG. The Flemish water assessment is found to be a useful tool to stimulate property owners to take mitigation measures but it rarely prevents building developments in flood-prone areas. Moreover, the 'space for water' discourse has recently been challenged by Flemish actors citing cost-efficiency concerns. According to the discourse of the so-called MultiLayer Water Safety (MLWS), FRG has to include an optimal mix of prevention, protection, and preparation measures (Kaufmann et al., 2016). This mix is obtained through cost-benefit analyses (CBA), which in some cases appear to give preference to local defence infrastructures over extensive 'space for water' measures (see VMM, 2014).

\section{Towards decreased fragmentation and enhanced coordination between governmental actors}

During the period investigated, initiatives were launched in both regions to improve coordination between all governmental actors involved (Mees et al., 2016). In Flanders, formal coordination at policymaking level has been established through the CIW, which assembles representatives from different water managers and the Flemish spatial planning department. A similar institution in Wallonia is the Interdepartmental Flood Group (GTI), but with a focus on integrated FRG rather than on water management at large. In addition, the Walloon government established a regional crisis centre in 2007 to coordinate its governmental divisions in the event of emergencies. At sub-basin level, the Walloon river contracts and Flemish sub-basin boards assemble local stakeholders to agree on an integrated approach.

\footnotetext{
${ }^{3}$ These are areas with a 'hard' spatial destination but which are important to the water system. The Flemish Government has promulgated a series of measures to control development in these areas.
} 
Besides measures to improve coordination, important steps were also taken in Flanders to increase the efficiency of water management by reducing the number of water managers. This resulted from the 2014 internal state reform, which provided municipalities with the possibility to transfer competences for their watercourses to the provinces. In addition, several polders and wateringues were abolished. Consequently, the number of water managers dropped from 424 to 196 in the investigated period.

Two International River Basin Districts cross the territories of the Flemish and Walloon Regions, namely the Scheldt and Meuse basin. To coordinate interregional policy making, several international and bilateral commissions are active, which function as platforms for transboundary coordination and information exchange, for example, the Flemish-Dutch Scheldt Commission, the International Scheldt Commission and International Meuse Commission. A discussion of the impact and effectiveness of these commissions goes beyond the scope of this paper. Important to mention, however, is that they help coordinate the requirements of the WFD and FD, among other things through the development of flood risk cartography and EU-financed projects.

\section{Towards shared flood risk responsibilities}

Particularly in Flanders, a strong policy discourse has emerged to share flood risk responsibilities with a wider range of actors (Mees et al., 2016). Competences and responsibilities for flood protection are not clearly defined by law but in practice they are perceived as the responsibility of governmental water managers. In 2013, however, the Flemish Environment Agency (VMM) launched the concept of MLWS, which calls for the use of flood prevention (i.e. spatial planning, property-level protection), protection (i.e. preventing floods) and preparedness (i.e. crisis management) measures (Cauwenberghs, 2013; CIW, 2015). This new approach implies that flood risk responsibilities should be shared between water managers and actors from other policy domains and society. As explained above, spatial planning has already been present for some time in FRG but recently, the involvement of emergency planners and citizens is also attracting increased attention.

In Wallonia, policymakers at regional level use a similar discourse, namely the 3Ps (prevention, protection, and preparedness) (Mees et al., 2016). Also here, increased involvement of spatial and emergency planners is expected and some cautious steps have been taken towards increasing citizens' knowledge on property-level protection (SPW, 2014). The responsibility of citizens in Wallonia, however, appears to be less emphasised in policy documents and stakeholder interviews than is the case in Flanders.
Another aspect of shared flood responsibilities pertains to the recovery strategy. An awareness-raising mechanism has been built into insurance coverage for flood events. Buildings constructed in high-risk areas after 23 September 2008 no longer benefit from the governmentally set cap on insurance fees, and can be refused coverage by insurers.

\section{Explaining governance dynamics}

In this section, an overview is given of the factors fostering and hampering stability and change within Belgian FRG. We indicate changes in the four dimensions of the policy arrangements (discourse, rules, actor coalitions, and resources) and explain per dimension which factors induce stability or change. Table 3 offers an overview of these explanatory factors per dimension.

\section{Explanatory factors in the discourse dimension}

Most of the shifts within Belgian FRG were initiated by the influx of a new discourse. The 1998 and 2002-2003 floods were triggering events that led to new legislation because they provided evidence for claims which had been made by nongovernmental organisation (NGOs) and public officials within the water and nature management administrations for many years, namely that water needs space. This narrative on space for water has formed part of a broader discourse on integrated water management, intensely advocated in international fora since the end of the 1980 s (Jeffrey and Gearey, 2006; Crabbé, 2008) and at EU level, mainly through the WFD. The 2007 EU FD initiated the MLWS and 3Ps discourse but it quickly gained popularity among regional water managers because it responded to their concerns that an exclusive focus on preventing floods and flood damage was no longer feasible.

The enthusiasm of regional water managers for the MLWS approach is countervailed by the reluctance of local authorities to apply it in practice. In general, municipal and provincial governments have a closer connection to their electorate, which makes the focus on shifting responsibilities and cost-efficiency politically hard to defend. Moreover, a certain discursive gap still remains between policy and practice when it comes to integrated water management and creating space for water. The water assessment, for instance, is already in praxis since 2006 but municipal spatial planners have applied it in a more consistent and stringent way only since the severe 2010 floods in the Scheldt basin and the subsequent legislative reform in 2011.

A huge barrier in terms of adaptive expectations is the low level of flood awareness among the Belgian population. Throughout the 20th century, FRG has become increasingly professionalised, which has put citizens in the shade of it; 
Table 3 Forces of stability and change within Belgian FRG

\begin{tabular}{|c|c|c|}
\hline Forces of stability & Dimensions of arrangements & Forces of Change \\
\hline $\begin{array}{l}\text { Adaptive expectations: } \\
\text { - Lack of public flood awareness } \\
\text { - FRG considered government } \\
\text { responsibility }\end{array}$ & Policy discourses & $\begin{array}{l}\text { Diminishing trust in existing institutions: Existing discourses } \\
\text { undermined by floods of 1998, 2002/03 and } 2010 \\
\text { New ideas, problem definitions and policy concepts: } \\
\text { - International discourse on integrated water } \\
\text { management } \\
\text { - MLWS and 3Ps discourse focusing on diversification of } \\
\text { strategies } \\
\text { - Cost-efficiency concerns, due to financial/economic } \\
\text { crises }\end{array}$ \\
\hline $\begin{array}{l}\text { Coordination effects: Multi-level and } \\
\text { multi-sector fragmentation }\end{array}$ & Policy actors and coalitions & $\begin{array}{l}\text { Entrepreneurs: VMM/DGO3 and other watercourse } \\
\text { managers in specific cases } \\
\text { Actor coalitions: MLWS coalition at Flemish level }\end{array}$ \\
\hline $\begin{array}{l}\text { Legislative lock-in: } \\
\text { Legislative impact of regional spatial } \\
\text { plans }\end{array}$ & Rules of the game & $\begin{array}{l}\text { External legislative pressures: EU Water Framework } \\
\text { Directive and Floods Directive, and also: EU Birds } \\
\text { Directive, Habitats Directive and Environmental Impact } \\
\text { Assessment Directive }\end{array}$ \\
\hline $\begin{array}{l}\text { Fixed costs and increasing returns: } \\
\text { Existing physical infrastructure and } \\
\text { spatial development }\end{array}$ & Power and resources & $\begin{array}{l}\text { Financial/economic developments: } \\
\text { Financial crisis, increased use of CBA } \\
\text { New expertise, learning effects: } \\
\text { Increased number of bio-engineers }\end{array}$ \\
\hline
\end{tabular}

they are rarely involved, neither in decision making nor in implementation (Patel and Stel, 2004; Schelfaut et al., 2011). This has led to the expectation among citizens that the government is exclusively responsible for preventing flood damage resulting in cultural path dependency (Mees et al., 2016).

\section{Explanatory factors in the actor dimension}

The discourse on MLWS was originally introduced by the Flemish Environment Agency (VMM) but has since been adopted by other water managers active in the Flemish Region. The Flemish water managers VMM, Waterwegen \& Zeekanaal, and De Scheepvaart form an advocacy coalition (see Wiering et al., 2018) defending the new approach towards actors involved at other governmental levels. There is more reluctance at provincial and municipal level concerning the implications of MLWS (see above).

Administrative bodies and their civil servants rather than politicians instigate innovation. In Flanders, the VMM can be considered as the main driving force behind the CIW in the integration of water management and spatial planning. Navigable and provincial water managers have also taken a number of innovative initiatives, e.g. nature-based FRG planning for the Scheldt and Meuse Rivers, expropriation policy in the Grote Nete valley. In Wallonia, the nonnavigable watercourse manager DGO3 is very active in the development of flood cartography, river contracts, etc. A public official within DGO2 (i.e. the navigable watercourse manager) was the driving force behind the establishment of the GTI and the Walloon Crisis Centre.

The regionalisation process, which started in the 1980s, increased the fragmentation of Belgian FRG in terms of actors and rules, but should be considered as a recentralisation at regional level rather than a decentralisation, i.e. the regional level has overtaken the central steering role of the federal level. In recent years, the fragmentation level in Flanders decreased due to shifts in competences or the abolition of organisations. These changes were in many cases enabled by windows of opportunity in the actor dimension, e.g. the retirement of certain public officials or politicians.

Both in Flanders and Wallonia, the high level of fragmentation constitutes a barrier to change. Innovations introduced by one organisation, e.g. the development of monitoring systems, are not automatically adopted by others. Hence, coordination effects can be witnessed, which lead to path dependency. In both regions, however, efforts are being made to boost the exchange of information between different organisations, e.g. through coordination platforms such as the abovementioned CIW and GTI.

Regarding different policy areas, it is observed that there is greater integration of water and spatial planning policy than between regional competences and the federal emergency planning and insurance policy. Nevertheless, huge potential exists in linking insurance policy with water and 
spatial planning policies, e.g. by incentivizing citizens to take measures such as adaptive building and flood proofing at property level. Hitherto, the necessary bridging mechanisms have not been sufficiently developed. This may in part be explained by the fact that the competences for these domains are scattered across different political levels.

\section{Explanatory factors in the rules dimension}

Changes in the discourse and actor dimensions have been institutionalised and reinforced by modifications in legislation. In Flanders, the introduction of the DIWP in 2003 represented the formal start of a new chapter in Flemish FRG. This decree took the integrated approach to water quantity and quality management further than the 2000 EU WFD. It forced managers to adopt a holistic water system approach, taking into account the impact of developments on the water system both inside and outside the riverbed. In the same year, the Walloon government launched its Plan PLUIES, which has a similar function. The Plan PLUIES has a narrower scope, addressing flood risks and not water management in general, but it also establishes a link with spatial planning through the development of flood cartography.

An explanation for the impact of the WFD on FRG in Belgium can be found in the fact that it was introduced after an important flood event in 1998, which demonstrated the need for a new approach. Throughout the 1990s, a number of public officials and politicians had attempted to create a holistic legislative framework on water policy but these attempts always failed (Crabbé, 2008). Combined with the recent flood experience, policy entrepreneurs within the Flemish administration and government were able to use the WFD to reach agreement on the DIWP. Three other EU directives fostered a nature-based FRG in Flanders, namely the Birds (79/409/ EEC) and Habitats (92/43/EEC) directives, and the Environmental Impact Assessment Directive (85/337/EEC). Particularly in the tidal Scheldt basin, these directives forced the Flemish water managers to search for alternative flood risk solutions, and encouraged a fruitful cooperation between water managers, NGOs, and nature managers.

Walloon actors also refer to the WFD as the driving force behind the shift towards natural flood management. In addition, the countrywide flooding of 2002-2003 once again strengthened the arguments of policy entrepreneurs for a more integrated approach.

The FD impacted legislation in Belgian FRG as well. The implementation of the FD in the DIWP (2010) and the Walloon Water Code (2010) resulted in a clearer and more comprehensive legal basis for FRG. The procedural requirements of the FD (such as the issuance of flood risk and flood hazard maps) have strengthened existing and developing instruments and provided a more solid framework for legislators and governments to take flood risk measures. In general, however, the impact of the FD on Belgian FRG has been greater in terms of discourse than rules, which can, among others, be explained by the lack of substantive requirements in the Directive.

The abovementioned 2005 Insurance Act constituted a significant trigger for change in the recovery arrangement. While before ex post compensation was governed exclusively by public funding, the efficiency of compensatory procedures increased through the involvement of the insurance industry (Suykens et al., 2016).

Despite significant improvements, the historical backlog of spatial planning in the rules dimension can be considered the Achilles heel of Belgian FRG. In the 1970s and 1980s, regional spatial plans were drafted that assigned land to a specific function (e.g. residential, industry, agriculture, nature). However, little attention was paid to the flood vulnerability of the land. This triggered the start of unrestrained and disparate building activities. Between 1976 and 2000, the built up area in some regions tripled and more than $20 \%$ of built up land in Flanders is situated in flood-prone zones (Poelmans and Van Rompaey, 2009; Poelmans et al., 2011). A similar situation can be found in the more densely populated areas of Wallonia. Hence, the regional spatial plans have led to a legislative and discursive lock-in. In strict legal terms, land indicated as 'residential' on the plan does not grant the owner the right to build on it, but in practice it is perceived as such. As a result, it appears infeasible in practice to reject a building permit based on water concerns, even when the location is recognised as flood-prone in flood cartography. Innovative flood risk prevention instruments, such as the water assessment, 'signal areas' and flood cartography, help to mitigate spatial planning's most perverse effects but truly preventing further harmful development in flood-prone areas remains a challenge.

\section{Explanatory factors in the power and resources dimension}

Several scholars note that flood defence infrastructure creates a levee effect; it stimulates human spatial development in flood-prone zones, which forces water managers to continuously invest in the maintenance and further development of defence infrastructure (White, 1945; Baan and Klijn, 2004; Bubeck et al., 2015). This levee effect can also be observed in Belgium. In several parts of the country, towns and cities have been developed in spite of the area's flood vulnerability. These developments make a radical change in FRG impossible because of fixed costs and increasing returns. 
Despite this levee effect, important investments in innovative flood protection and spatial planning measures have taken place. The 1998 floods in Flanders and 2002-2003 floods in Wallonia demonstrated the inadequacy of the classical defence approach and offered a window of opportunity for water managers to acquire funding to invest in 'space for water' measures. As a result of the 'ecological turn' in FRG, bioengineering expertise has been developed within water management organisations (Mees et al., 2016).

From 2008 onwards, the economic crisis acted as another catalyst for flood risk policy development. Most governmental organisations involved in FRG claim not to have been severely impacted in terms of direct financial cutbacks, but they have been confronted with a decrease in personnel. The case is different for many crisis managers, who face a deficit both in material and human resources. Together with rising flood risks, the economic crisis gave room for a discourse focused on cost efficiency in Flanders, which has since come to the fore in the MLWS approach. During the investigated period, the use of CBA has grown significantly.

\section{Discussion}

Between 1995 and 2015, a number of significant shifts can be witnessed within Belgian FRG, leading to more coordination, more space for water, a wider variety of flood risk strategies and a shift of responsibilities.

In 2003, the Flemish DIWP and Walloon Plan PLUIES institutionalised the existing discourses of 'space for water' and integrated water management. In this case, change was initiated in the discourse dimension, whereas a triggering event (flooding) and external legislative pressure (EU WFD) were used to build a strong advocacy coalition in order to have the new approach discursively structurated and institutionalised. By discourse structuration, we mean that a broad range of actors adopt the particular discourse (Hajer, 1995). Discourse institutionalisation takes place when the discourse is set in legislation, policy documents, etc. The discourse coalition included public officials at various echelons, next to the Green Party and its minister (Crabbé, 2008). In terms of the modes of gradual transformation (Streeck and Thelen, 2005), the change in Flanders was primarily characterised by displacement, namely the replacement of previous with new legislation. In Wallonia, the Plan PLUIES came on top of existing legislation, i.e. layering. After the new rules were introduced, change on the ground happened incrementally through a process of conversion; the existing institutions (i.e. water managers and spatial planning departments) adapted themselves to new goals and interests.
After the short period of radical (legislative) change in 2003, FRG developed very incrementally and not all changes introduced by the DIWP and Plan PLUIES were well observed by the lower echelons of government, e.g. inadequate application of the water assessment. This stemmed from the complexity of the new legislation, the lack of discourse structuration at the lower levels of government and insufficient supervision by higher authorities. To enable a better adoption of the new legislation at local level, another trigger event was needed, namely the floods in 2010. This flooding demonstrated once again the importance of providing space for water and coordination between actors, thereby opening a new window of opportunity (Kingdon, 1984). It created awareness among spatial planning actors and municipal politicians and consequently enabled discourse structuration. In addition, the DIWP in Flanders was evaluated and reformed to improve its implementation, e.g. by simplifying and streamlining plans and procedures. Next to that, new spatial planning instruments were developed. We can thus conclude that change evolved in the opposite direction to the first shifts. This time, legislation was already in place but a trigger event was needed to reach sufficient discourse structuration to (a) amend rules and (b) have them implemented on the ground.

At the same time, the floods in 2010 supported the development of new advocacy coalitions and discourses at regional level regarding MLWS (Flanders) and the 3Ps (Wallonia). These discourses articulated the long, prevalent frustration among water managers to be perceived as solely responsible for flood damage prevention. The main policy entrepreneurs of the new approach are the regional water manager VMM in Flanders and DGO3 in Wallonia. A first window of opportunity for these policy entrepreneurs to strengthen their position was the introduction of the 2007 EU FD, which advocated paying attention to prevention, protection, and preparedness measures. A second window was created by the 2010 floods, which showed that the existing institutions were insufficient. The low economic conjuncture also functioned as a facilitating factor, since MLWS (and to a lesser extent the 3Ps discourse) pays particular attention to cost efficiency. In subsequent years, the MLWS discourse came to be supported by a strong advocacy coalition at regional level and has now been integrated in several policy documents. The extent to which it reaches the required structuration among local government and the population remains unclear at this stage. The shift to MLWS can be considered as a process of conversion and layering; the dominant actors of FRG redefine their role and involve additional actors in the governance process.

So what is the impact of the fragmented MLG structure in terms of stability and change? In the Introduction, we expected that fragmentation could have both a fostering and a hampering influence on change, and our findings 
appear to confirm this. In many cases, the fragmented competences between different organisations, policy sectors, and governmental levels led to negative coordination effects, thus hindering the spread of innovation. However, the fact that the country has undergone a number of radical institutional reforms since the 1980s has led to a government structure that is not only fragmented but also in constant change. This structure creates a higher number of entry points for new ideas to develop than would probably be the case in a stable, centralised structure. Kaufmann et al. (2016) indeed find that, in comparison to the Netherlands, Flemish FRG has been more accessible for the MLWS discourse, partly due to its more open character.

\section{Conclusion}

In this article, we addressed stability and change in Belgian FRG between 1995 and 2015. The paper describes the shifts that have taken place (section Dynamics in Belgian FRG), through which kind of transformation processes they have developed and how these changes (or their absence) can be explained (Section Explaining Governance Dynamics). By using the PAA approach, the paper explores how actors, rules, discourses, and resources interact in fostering change and stability.

Overall, Belgian FRG was rather dynamic in the investigated period. Changes took place primarily in the dimensions of discourses, rules, and, to a lesser extent, actors. Hereby, floods functioned as windows of opportunity. The flood events enabled actors to anchor already existing discourses in legislation, e.g. after the floods in 1998 and 2003, or to spread discourses using existing legislation, as was the case after the 2010 flood. Hence, the actors, rules, discourses, and resources dimensions of the PAA appear as highly intertwined in the process of change and stability.

Between the shock events caused by flooding, the process of change took place incrementally. Several of Streeck and Thelen's modes of transformation could be recognised. We noticed displacement of existing legislation in Flanders and layering of legislation in Wallonia and we could also point to the process of conversion within water management organisations and spatial planning departments, whereby the organisations adapted themselves to new goals and interests.

Despite considerable change, obstructing factors hampered a number of innovations desired by stakeholders. The main stability factors found in Belgian FRG were adaptive expectations, legislative lock-ins, fixed costs of existing infrastructure and coordination effects.

Particular attention was paid in this article to the role of fragmentation. In many cases, FRG fragmentation within and between policy areas, and between governmental levels, was shown to hamper change. Conversely, the institutional and administrative adjustments and reforms the country has undergone since the 1970s have created a certain openness of the governance arrangement. As a result, there is a high number of entry points for innovative concepts to enter the arrangement. If well-coordinated, a fragmented governance structure can thus facilitate policy innovation (see also Termeer et al., 2011).

\section{Acknowledgements}

This paper has been written in the framework of the EUfunded FP7 project STAR-FLOOD. This research has received funding from the European Commission under grant agreement no. 308364 .

\section{References}

Baan P.J.A. \& Klijn F. Flood risk perception and implications for flood risk management in the Netherlands. Int J River Basin Manage 2004, 2, 113-122.

Bubeck P., Kreibich H., Penning-Rowsell E., Botzen W.J.W., de Moel H. \& Klijn F. Explaining differences in flood management approaches in Europe and the USA: a comparative analysis. Journal of Flood Risk Management 2015, 10, (4).

Cauwenberghs, K. Meerlaagse waterveiligheid: resultaten van de ORBP-studie. Presentation at VMM Symposium 'Meerlaagse Waterveiligheid. VMM, Antwerpen. 2013. https://www.vmm. be/evenementen/presentaties/symposium-meerlaagsewaterveiligheid (accessed 12 September 2013).

CIW. Informatienota Meerlaagse Waterveiligheid. 2015. http:// www.integraalwaterbeleid.be/nl/kalender/infonota Meerlaagse\%20Waterveiligheid.pdf (accessed 23 February 2016).

Crabbé A. Integraal waterbeleid in Vlaanderen: van flü̈de naar solide. Antwerp: Universiteit Antwerpen, 2008.

Hajer M. The politics of environmental discourse. Ecological modernization and the policy process. Oxford: Oxford University Press, 1995.

Jeffrey P. \& Gearey M. Integrated water resources management: lost on the road from ambition to realisation? Water Sci Technol 2006, 53, (1), 1-8.

Kaufmann M., Mees H., Liefferink D. \& Crabbé A. A game of give and take - the introduction of multi-layered safety in the Netherlands and Flanders. Land Use Policy 2016, 57, 277-286.

Kingdon J. Agendas, alternatives, and public policies. Boston: Little Brown \& Co, 1984.

Mees H., Suykens C., Beyers J.C., Crabbé A., Delvaux B. \& Deketelaere K. Analysing and evaluating flood risk governance in Belgium. Dealing with flood risks in an urbanised and institutionally complex country. Leuven: University Antwerp and Catholic University of Leuven, 2016. 
Mees H., Tempels B., Crabbé A. \& Boelens L. Shifting publicprivate responsibilities in Flemish flood risk management. Towards a co-evolutionary approach. Land Use Policy 2016, 57, 23-33.

Patel M., \& Stel J.H. Public participation in river basin management in Europe. a national approach and background study synthesising experiences of 9 European countries. Workpackage 4 of the HarmoniCOP Project, University of Maastricht, 2004.

Poelmans L. \& Van Rompaey A. Detecting and modelling spatial patterns of urban sprawl in highly fragmented areas: a case study in the Flanders-Brussels region. Landsc Urban Plan 2009, 93, (1), 10-19.

Poelmans L., Van Rompaey A., Ntegeka V. \& Willems P. The relative impact of climate change and urban expansion on peak flows: a case study in central Belgium. Hydrol Process 2011, 25, 2846-2858.

Schelfaut K., Pannemans B., van der Craats I., Krywkow J., Mysiak J. \& Cools J. Bringing flood resilience into practice: the FREEMAN project. Environ Sci Policy 2011, 14, 825-833.

SPW Inondations. Namur: Réduire la vulnérabilité des constructions existantes. SPW, 2014.

Streeck W. \& Thelen K. Beyond continuity: explorations in the dynamics of advanced political economies. Oxford: Oxford University Press, 2005.

Suykens C., Priest S., Van Doorn-Hoekveld W., Thuillier T. \& van Rijswick M. Dealing with flood damages: will prevention, mitigation and ex-post compensation provide for a resilient triangle? Ecol Soc 2016, 21, (4).
Termeer C., Dewulf A., Van Rijswick H., Van Buuren A., Huitema D., Rayner T. \& Wiering M. The regional governance of climate adaptation: a framework for developing legitimate, effective, and resilient governance arrangements. Clim Law 2011, 2, 159-179.

Van Tatenhove J., Arts B. \& Leroy P., eds Political modernisation and the environment. The renewal of environmental policy arrangements. Dordrecht: Kluwer Academic Publishers, 2000.

VMM Onderbouwing van het Overstromingsrisicobeheerplan van de onbevaarbare waterlopen. ORBP-analyse Basisrapport. Erembodegem: VMM, 2014 https://www.vmm.be/publicaties/ orbp-analyse-basisrapport (accessed 3 March 2015).

White G.F. Human adjustments to floods. Department of Geography Research, Paper 29, University of Chicago, Chicago, 1945

Wiering M., Liefferink D. \& Crabbé A. Stability and change in flood risk governance: on path dependencies and change agents. Journal of Flood Risk Management 2018, 11, (3), 230-238.

\section{Supporting information}

Additional supporting information may be found in the online version of this article at the publisher's website: http://onlinelibrary.wiley.com/doi/10.1111/jfr3.12330/ suppinfo.

Appendix S1. List of interviews. 